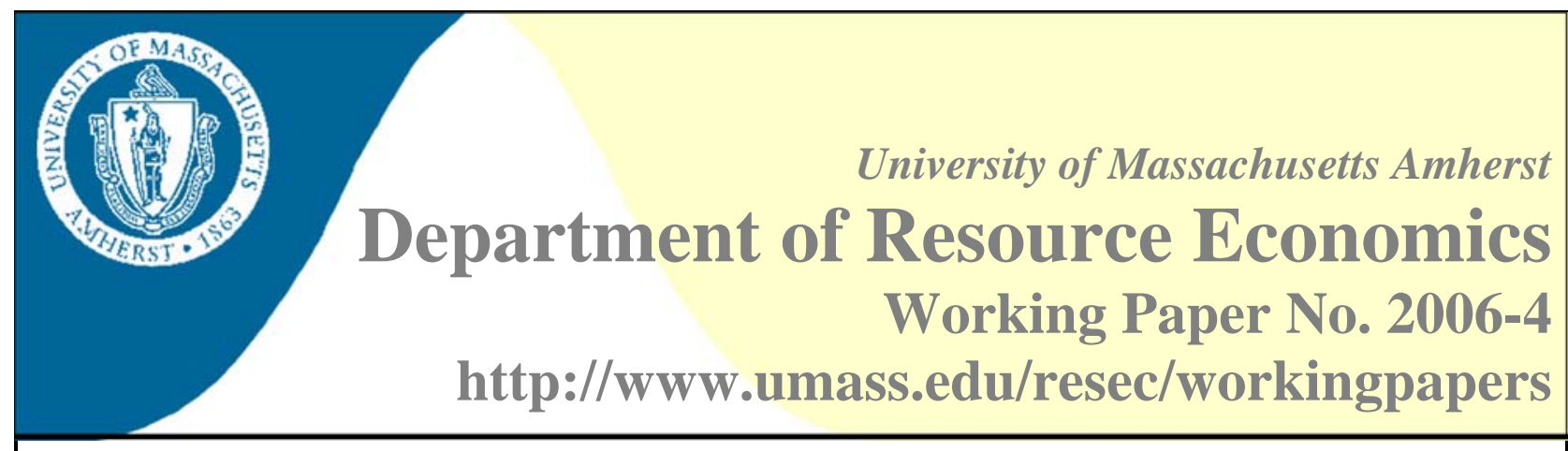

\title{
Within and Between Group Variation of Individual Strategies in Common Pool Resources: Evidence from Field Experiments
}

\author{
Maria Alejandra Velez ${ }^{1}$, James J. Murphy ${ }^{2}$, and John K. Stranlund ${ }^{3}$
}

\section{Abstract:}

With data from framed common pool resource experiments conducted with artisanal fishing communities in Colombia, we estimate a hierarchical linear model to investigate within-group and between-group variation in individual harvest strategies across several institutions. Our results suggest that communication serves to effectively coordinate individual strategies within groups, but that these coordinated strategies vary considerably across groups. In contrast, weakly enforced regulatory restrictions on individual harvests (as well as unregulated open access) produce significant variation in the individual strategies within groups, but these strategies are roughly replicated across groups so that there is little between-group variation.

Keywords: common pool resources, field experiments, communication, regulation, hierarchical linear models

JEL Classification: C93, H41, Q20, Q28.

\footnotetext{
${ }^{1}$ Maria Alejandra Velez, Department of Resource Economics

University of Massachusetts, Stockbridge Hall, 80 Campus Center Way, Amherst, MA 01003

E: majavelez@gmail.com F: 413-545-5853

${ }^{2}$ James J. Murphy, Department of Resource Economics

University of Massachusetts, Stockbridge Hall, 80 Campus Center Way, Amherst, MA 01003

E: murphy@resecon.umass.edu P: 413-545-5716 F: 413-545-5853

${ }^{3}$ John K. Stranlund, Department of Resource Economics

University of Massachusetts, Stockbridge Hall, 80 Campus Center Way, Amherst, MA 01003

E: stranlund@resecon.umass.edu P: 413-545-6328 F: 413-545-5853
} 
March 2006

\title{
Within and Between Group Variation of Individual Strategies in Common Pool Resources: Evidence from Field Experiments
}

\author{
MARIA ALEJANDRA VELEZ \\ Department of Resource Economics \\ University of Massachusetts-Amherst \\ JAMES J. MURPHY* \\ Department of Resource Economics \& \\ Center for Public Policy and Administration \\ University of Massachusetts-Amherst \\ JOHN K. STRANLUND \\ Department of Resource Economics \\ University of Massachusetts-Amherst
}

\begin{abstract}
Acknowledgements
We thank Maria Claudia Lopez and members of the Faculty of Environmental and Rural Studies at Javeriana University in Bogotá, Colombia for providing outstanding support for our work in the field. At each site, the experiments would not have been possible without the assistance of local leaders who helped the research team develop credibility with local community members. We are also indebted to WWF-Colombia for coordinating the fieldwork in the Pacific Region. We received valuable comments from Juan Camilo Cardenas, Samuel Bowles, James Boyce, and Sylvia Brandt. Wendy Varner and Susanne Hale provided valuable administrative support. We assume complete responsibility for the final contents of this paper.
\end{abstract}

* Correspondence to James Murphy, Department of Resource Economics, 219A Stockbridge Hall, University of Massachusetts-Amherst, Amherst, MA 01003, USA. Phone: (413)545-5716 Fax: (413)545-5853, E-mail: murphy@resecon.umass.edu. 


\title{
Within and Between Group Variation of Individual Strategies in Common Pool Resources: Evidence from Field Experiments
}

\begin{abstract}
With data from framed common pool resource experiments conducted with artisanal fishing communities in Colombia, we estimate a hierarchical linear model to investigate withingroup and between-group variation in individual harvest strategies across several institutions. Our results suggest that communication serves to effectively coordinate individual strategies within groups, but that these coordinated strategies vary considerably across groups. In contrast, weakly enforced regulatory restrictions on individual harvests (as well as unregulated open access) produce significant variation in the individual strategies within groups, but these strategies are roughly replicated across groups so that there is little between-group variation.
\end{abstract}

JEL Classification: C93, H41, Q20, Q28,

Keywords: common pool resources, field experiments, communication, regulation, hierarchical linear models

\section{Introduction}

In many economics experiments, individual subjects are assigned to a particular group and are then asked to make a sequence of decisions over multiple rounds. In a multi-period game, clearly the observations generated by a single individual are not independent, and the repeated measures are usually captured with random effects models. However, the hierarchical, or nested, structure of the data implies that the observations from different individuals within a group are also unlikely to be statistically independent.

Hierarchical linear models can be used to model both groups and individuals as random effects. ${ }^{1}$ These types of models are commonly used, for example, in educational performance studies with pupils nested within schools, in family studies with children nested within families, and medical research with patients nested within hospitals (Singer 1998, Hox 1998, Boyle and Willms 2001). These models provide statistically efficient estimates of regression coefficients (Goldstein 1995), they avoid misleading standard errors, confidence intervals and significance

\footnotetext{
${ }^{1}$ Hierarchical linear models are also known as “multilevel regression models.”
} 
tests produced by when one fails to account for clustered data (Hox 1998), and they allow the analyst to decompose the explained variance in the dependent variable by level of hierarchywhich is the primary focus of this paper. ${ }^{2}$

Our interest in using hierarchical linear models is to gain a deeper understanding of the effects of alternative institutions designed to promote more conservative choices in common pool resource experiments than one can obtain from a random effects model that fails to account for the nested structure of the data. We ask whether accounting for group effects can explain individual decisions for particular institutions, and, more importantly, how these effects may vary across institutions. We conducted a series of common pool resource experiments with artisanal fishermen in rural Colombia. Each group of five subjects first played 10 rounds of a standard open access common pool resource game and then 10 additional rounds under one of three institutions. One institution allowed subject to communicate between rounds. This treatment is meant to capture the effects of informal non-binding agreements on individual harvests. ${ }^{3}$ Under the other two institutions, subjects could not communicate. Instead, they faced an exogenously imposed quota restriction on their harvests, which was enforced with random monitoring and a unit penalty for exceeding the quota. These two regulatory institutions were identical except that they had different marginal penalties for noncompliance to the quota.

We find that each of the three second-stage institutions motivated individuals toward more conservative exploitation of the resource than under the baseline open access treatment. In fact, mean harvest levels in the second-stage treatments were statistically indistinguishable.

\footnotetext{
${ }^{2}$ To our knowledge, hierarchical linear models have rarely been used to analyze data from economics experiments. Exceptions include Kurzban et al. (2001), and Messer et al. (2005). However, these papers do not analyze the relative importance of within-group and between-group variation in individual choices or how these values may change with different experimental treatments.

${ }^{3}$ For a recent review of the effects of communication in common pool experiments see Cardenas, Ahn and Ostrom 2003.
} 
Stopping at this point, however, would make us miss a rich story about the underlying variation in individual choices that led to these similar outcomes. Our application of a hierarchical linear model yields estimates of between-group and within-group variances that differ in important ways across the institutions. Under open access and the two regulatory institutions, the variation in individual harvests is explained more by differences within groups than by differences between groups. The opposite occurs under the communication treatment: while the withingroup variation is quite low in this treatment, the between-group variation is significant.

Under open access and the regulatory institutions, individuals made their choices in private, and hence, were not subject to the direct influence of others in their group. Under these conditions, we expect that individuals with different preferences will formulate different strategies. Individuals may be Nash maximizers, altruists, conformists, reciprocators, etc., and several of these "types" are likely to be represented in any given group. ${ }^{4}$ Therefore, it is not surprising that subject heterogeneity would lead to a high degree of within-group variation in individual choices in our non-communication treatments. That we also observe low betweengroup variation in these treatments suggests that the composition of individual "types" is roughly replicated across groups.

Communication, on the other hand, can serve as a mechanism to share information about the problem at hand, while bringing social pressure to bear on individuals to achieve more efficient outcomes. In this way, communication can lead to informal agreements among group members that are non-binding, but nevertheless serve to coordinate individual actions. Our results suggest that this coordination function of communication led to low within-group

\footnotetext{
${ }^{4}$ Several authors have sought to account for different individual "types" in public goods experiments, including Offerman et al. (1996), Keser and Van Winden (2000), Brandts and Scharm (2001), Brosig (2001), Fischbacher et al. (2001), Cason et al. (2004), Kurzban and Houser (2005). See Casari and Plot (2003) for an attempt to classify individual types in a common pool experiment.
} 
variation in individual choices. However, we simultaneously observe significant between-group variation in individual choices, suggesting a high degree of heterogeneity in the coordinated strategies that different groups are able to formulate and maintain.

\section{Experimental Design}

Our experiments are based on the standard problem of individual harvests from a common pool resource by $n$ identical individuals. Individual payoffs were derived from a model that is similar to that presented by Ostrom et al. (1994), and an earlier model developed by Cornes and Sandler (1983). Individual $i$ harvests $x_{i}$ units up to a capacity constraint $x_{i}^{\max }$. Units of harvest sell at a constant price $p$. The individual's harvest costs are $c\left(x_{i}+x_{-i}\right)+d x_{i}\left(x_{i}+x_{-i}\right)$, where $x_{-i}=\sum_{j \neq i} x_{j}$, and $c$ and $d$ are positive constants. The individual has an endowment $e_{i}$. Thus, individual payoffs are:

$$
\pi_{i}=e_{i}+p x_{i}-c\left(x_{i}+x_{-i}\right)-d x_{i}\left(x_{i}+x_{-i}\right), \text { subject to } x_{i} \leq x_{i}^{\max } \text {. }
$$

The experiments were conducted in rural villages of Colombia during the summer of 2004 in communities in which the primary activity is artisanal fishing. Rather than use a neutral frame, we were explicit that the experiments concerned harvest decisions from a shared fishery. ${ }^{5} \mathrm{~A}$ total of 180 individuals participated in our experiments, divided into 36 groups of five. ${ }^{6}$ Each subject received an identical payoff table that was generated from [1] with parameters $p=116.875, c=$

\footnotetext{
${ }^{5}$ Within their recent taxonomy of field experiments, Harrison and List (2004) would classify our experiments as framed field experiments, because our experiments are conducted with a population of subjects for which the phenomenon of interest to us (behavior in a common pool fishery) is also an important element of the subjects' experiences.

${ }^{6}$ Assignment to groups was not completely random. We tried to ensure that relatives were in separate groups.
} 
17.875, $d=2.75, e_{i}=900, x_{i}^{\min }=0$ and $x_{i}^{\max }=8 .{ }^{7}$ With these values, the standard symmetric

Nash equilibrium is achieved when each individual chooses to harvest six units, while the efficient choice is one unit.

Subjects played a total of 20 rounds, divided into a pair of 10-round stages. For all 36 groups, the first stage was a typical unregulated common pool resource game (Open Access). In the second stage, we introduced one of the following three institutions (with 12 groups in each): face-to-face verbal communication (Com); external regulation with a low penalty (Low Penalty) or a medium penalty (Mid Penalty). In the Com treatment, each round participants were free to discuss the experiments prior to making their harvest decisions privately.

For the two treatments with an external regulation, an individual harvest quota of one unit (the efficient outcome) was imposed. To enforce the quota, each subject faced an audit

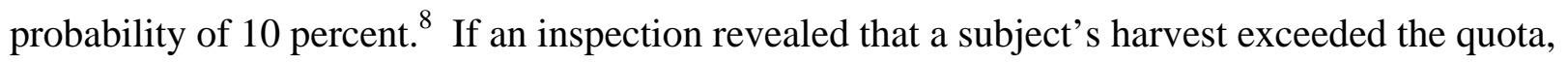
then that person incurred a financial penalty. The results of inspections were not made public. The two regulatory treatments differ only in the level of the unit penalty for discovered violations of the harvest quota. For the Low Penalty treatment, the fine was 27 pesos for each unit above the quota. With this penalty, the resulting marginal expected penalty is insufficient to change the pure Nash strategy equilibrium from the baseline Open Access harvest of six units per person. Nevertheless, such a regulation might serve to reduce individual harvests because of the frame the regulation places on the experiment, in particular the signal of efficient choices and

\footnotetext{
${ }^{7}$ Experiment instructions, including the payoff table, are available upon request. <INCLUDED AS

REVIEWER'S APPENDIX>. In the experiments, participants were asked to choose a harvest level between one and nine units, instead of between zero and eight. The reason for this shift is that the concept of zero harvest is very difficult to explain in the field since the participants depend so critically on their use of local natural resources. The payoff table they were given was modified to account for this. However, our analysis assumes that individual harvests vary from zero and eight.

${ }^{8}$ To decide who in a group, if anyone, was inspected in a particular round, a ballot was chosen (with replacement) from a bag containing five ballots containing the participants' numbers and five blank ballots.
} 
that deviations from the quota will be sanctioned. The Mid Penalty treatment involved the same regulatory frame, but the marginal penalty for violations of the quota was 165 pesos. A conventional model of regulatory enforcement predicts that this penalty would motivate subjects to reduce their harvests to five units.

In addition to deciding upon a level of harvest, subjects were also asked to state their expectation of what the others in their group would harvest in aggregate. ${ }^{9}$ After all subjects had made their decisions, the monitor collected this information and announced the total harvest for that round. With this information, individuals were able to calculate the total harvests by the others in their group and their individual payoffs.

Individual earnings ranged between 11,220 and 22,900 pesos with an average of 15,092 pesos (about US\$6.00). ${ }^{10}$ Earnings were paid in cash at the end of each experiment. Each experiment lasted about three hours. Before each experiment began, instructions were read aloud by the monitor and several practice rounds that did not count toward final earnings were played to familiarize the participants with the experiment.

\section{Estimation Technique: A Hierarchical Linear Model}

To formally test how both individual and group effects explain variation in individual harvest decisions, we estimated the following hierarchical linear model with random and fixed effects:

$$
\begin{aligned}
x_{j i t}= & \beta_{0}+u_{0 j}+v_{0 j i}+\left(\beta_{1}+u_{1 j}+v_{1 j i}\right) \text { Com } \\
& +\left(\beta_{2}+u_{2 j}+v_{2 j i}\right) \text { LowPenalty }+\left(\beta_{3}+u_{3 j}+v_{3 j i}\right) \text { MidPenalty } \\
& +\beta_{4} x_{j i t}^{e}+\text { Round }\left(\beta_{5}+\beta_{6} \text { Com }+\beta_{7} \text { LowPenalty }+\beta_{8} \text { MidPenalty }\right)+\varepsilon_{j i t} .
\end{aligned}
$$

\footnotetext{
${ }^{9}$ Other studies that use the expectations about other group members include Yamagishi and Sato (1986), Komorita et al. (1992), Bornstein and Ben-Yossef (1994), and Croson (1998).

${ }^{10} \mathrm{~A}$ day's wage in the regions where the experiments were conducted varied between 10,000 and 15,000 pesos.
} 
In equation [2], we model individual harvest decisions, $x_{j i t}$, for group $j$, subject $i$ and round $t$, as a function of dummy variables Com, LowPenalty, and MidPenalty that capture changes in individual harvests relative to Open Access for the three second-stage institutions. $x_{j i t}^{e}$ is individual $i$ 's expectation of the total harvest by the other four members of her group. Round and its interactions with each institution are included to control for the effect of time across treatments. The coefficients $\beta_{0}$ through $\beta_{8}$ are the fixed effects. We vary the coefficients for the treatments across both groups and individuals, and thus we estimate a random intercept model. For each treatment $k$, the group-level random effects are $u_{k j}$, and the individual random effects are $v_{k j i}$. The random error, $\varepsilon_{j i t}$, is assumed to be normally distributed with zero mean and variance $\sigma^{2}$

In this paper, we are primarily interested in the between- and within-group variances and how these vary across the institutions. There are four between-group variances: $\operatorname{var}\left(u_{0 j}\right)=\sigma_{u 0}^{2}$ for Open Access, $\operatorname{var}\left(u_{1 j}\right)=\sigma_{u 1}^{2}$ for Com, $\operatorname{var}\left(u_{2 j}\right)=\sigma_{u 2}^{2}$ for Low Penalty, and $\operatorname{var}\left(u_{3 j}\right)=\sigma_{u 3}^{2}$ for Mid Penalty. The four within-group variances are: $\operatorname{var}\left(v_{0 j i}\right)=\sigma_{v 0}^{2}$ for Open Access, $\operatorname{var}\left(v_{1 j i}\right)=\sigma_{v 1}^{2}$ for Com, $\operatorname{var}\left(v_{2 j i}\right)=\sigma_{v 2}^{2}$ for Low Penalty, and $\operatorname{var}\left(v_{3 j i}\right)=\sigma_{v 3}^{2}$ for Mid Penalty. The covariances between treatments are assumed to be zero.

\section{Results}

The mean harvest in the stage one Open Access baseline treatment (periods 1-10) was 4.75 units per person. This is lower than Nash equilibrium (six units), but higher than the efficient outcome (one unit). This pattern of under-extraction relative to the Nash equilibrium is consistent with that observed by Cardenas et al. $(2000,2002)$ in other Colombian communities using a similar 
protocol. In the second stage of each experiment (rounds 11-20), we introduced one of the three institutions. On average, the three institutions were equally effective at promoting conservation of the common pool resource: the mean individual harvest in the Com, Low Penalty and Mid Penalty treatments were $3.11(\sigma=2.46)$, $3.24(\sigma=2.66)$, and $3.15(\sigma=2.68)$, respectively. Obviously, however, such an aggregated analysis likely masks significant differences among individuals and groups.

In Table 1 we report the estimation results of the hierarchical linear model in equation [2]. Although the coefficients on the Com, Low Penalty and Mid Penalty fixed effects are negative and highly significant, there is no statistically significant difference among them $(p=$ 0.81 ), confirming that overall these institutions were equally effective at motivating more conservative harvest choices. Note, however, that the coefficients for Round $\times$ LowPenalty and Round $\times$ MidPenalty are both positive and significant (but not statistically different from each other, $p=0.43$ ). Thus, consistent with the results of Cardenas et al. (2000), the effectiveness of the Low Penalty and Mid Penalty regulations deteriorated over time, whereas the effectiveness of communication remained stable. $\leq$ INSERT TABLE 1 ABOUT HERE $>$

Now turn to the random components of our model. Our primary interest lies in examining the extent to which these random effects (both within- and between-groups) account for the variance in individual harvest decisions across treatments. When examining the variance estimates in Table 1, a clear pattern emerges: for the Com treatment, most of the variation is explained by between-group effects, whereas the within-group effects dominate in the three noncommunication treatments. In the Com treatment, the between-group variance $\left(\sigma_{u 1}^{2}=0.98\right)$ is 
statistically significant, but the within-group variance $\left(\sigma_{v 1}^{2}=0.03\right)$ is not. ${ }^{11}$ Moreover, this within-group variance is quite low, both in absolute terms and relative to the between-group variance. Therefore, outcomes in the Com treatment are explained more by differences among the groups than by individual differences within these groups. These results suggest that communication is effective at coordinating individual strategies within groups (low within-group variance), but that these coordinated strategies are quite variable across groups (high betweengroup variance).

Under the Open Access, Low Penalty, and Mid Penalty treatments, matters are much different. The between-group variances for these treatments are not significant. In fact, the estimated between-group variance under Open Access $\left(\sigma_{u 0}^{2}\right)$ is equal to zero, indicating substantial homogeneity among the 36 groups in the first stage. Moreover, the within-group variances under Open Access, Low Penalty, and Mid Penalty are much higher than the corresponding between-group variances. For example, the within-group variance under Low Penalty $\left(\sigma_{v 2}^{2}=3.01\right)$ is more than 37 times higher than the between-group variance $\left(\sigma_{u 2}^{2}=0.08\right)$; a similar patter holds for Open Access and Mid Penalty. Overall, then, we have no statistically significant between-group variation under our three non-communication treatments, but highly significant within-group variation; the reverse is true for the communication treatment. Moreover, the between-group variances under our non-communication treatments are much lower than the between-group variance under Com, but the within-group variances are much greater. These results reveal substantial variation in the strategies of individuals within

11 These estimates are unbiased, but we must treat the reported significance tests with caution because the standard errors and the Wald Z tests are valid only asymptotically (SAS Institute Inc., 1999). Since the variance estimates are unbiased, however, we can draw conclusions about the relative importance of within-group and betweengroups factors, and compare these estimates across treatments. 
groups when the subjects are not allowed to communicate, but that these strategies are roughly replicated across groups so that there is little variation among groups.

There are, however, noticeable differences in the within-group variances for the noncommunication treatments. First, the within-group variance estimates for Low Penalty (3.01) and Mid Penalty (1.90) are higher than the within-group variance estimate under Open Access (0.71). Thus, even though the two regulation treatments produced more conservative strategies than under Open Access, it appears that the uncertainty introduced by random monitoring and penalties to enforce the harvest quota also increased the within-group variation in individual strategies.

Furthermore, the within-group variation is less under the Mid Penalty regulation than under the Low Penalty regulation (3.01 versus 1.90). These treatments are identical, except that the Mid Penalty regulation has a fine for exceeding the harvest quota that is over six times that of the Low Penalty regulation. Thus, the Mid Penalty regulation involves a much stronger signal of the consequences of violating the quota. It appears that this stronger signal served to coordinate individual strategies more effectively than the lower penalty in the Low Penalty treatment. It is interesting, however, that the Mid Penalty regulation did not produce more conservative choices than the Low Penalty regulation.

Finally, we also estimated the model in Table 1 without modeling groups as random effects. ${ }^{12}$ The estimated coefficients of the fixed effects do not change appreciably from those reported in Table 1, although their significance levels change slightly due to lower standard errors. (Recall that one of the reasons for using hierarchical linear models is to avoid misleading standard errors produced by not adjusting for clustered data.) Therefore, not modeling groups as

\footnotetext{
${ }^{12}$ Estimation results are available upon request.
} 
random effects would have led us to the same conclusions about the effectiveness of the secondstage institutions in promoting more conservative harvests of the common pool resource.

However, we would have missed our deeper conclusions about how the underlying variation in individual strategies within and across groups varies across institutions.

\section{Concluding Remarks}

We use a hierarchical linear model to analyze how within-group and between-group variances in individual harvest strategies from a common pool resource vary across institutions. From field experiments conducted in rural Colombia, we find that communication and weakly-enforced regulatory designs yield similar reductions in average harvests from an unregulated open access baseline. Communication serves to effectively coordinate individual strategies within groups, but these group-coordinated strategies can vary significantly across groups. In contrast, regulatory designs yield a high level of within-group variation in individual strategies, but little variation across groups.

These results may have significant implications for the performance of non-binding community-based agreements to conserve common pool resources and the role of government interventions to do the same. While our results suggest that non-binding agreements are likely to be effective at coordinating individual decisions within a group or community, our results also suggest that there may be significant variation in the effectiveness and the forms of these verbal agreements across similar communities.

When the government intervenes, however, our results suggest that it can expect that its regulations will produce similar conservation efforts across similar communities. Moreover, this is bound to be true even when regulations are poorly enforced. On the other hand, our results 
also suggest that individual decisions within communities may vary quite a bit when regulations are implemented. However, a higher unit penalty for violating the harvest quota significantly reduced the within-group variation of individual strategies in our regulatory treatments, even though this higher penalty did not produce more conservative aggregate harvests. This may suggest that within-community variation in individual harvest decisions is a declining function of the stringency with which a regulation is enforced. That is, highly variable individual decisions within regulated communities may simply be due to the weak enforcement of regulatory controls that are characteristic of government interventions in common pool resource dilemmas in the developing world. 
Table 1: Estimation Results from Equation [2] using a Hierarchical Linear Model

\begin{tabular}{|c|c|c|}
\hline Fixed Effects - Coefficients & Estimate & $\begin{array}{c}\text { Standard } \\
\text { Errors }\end{array}$ \\
\hline Intercept $\left(\beta_{0}\right)$ & $3.13 * * *$ & 0.14 \\
\hline $\operatorname{Com}\left(\beta_{1}\right)$ & $-1.00 * * *$ & 0.35 \\
\hline Low Penalty $\left(\beta_{2}\right)$ & $-1.40 * * *$ & 0.31 \\
\hline Mid Penalty $\left(\beta_{3}\right)$ & $-1.63 * * *$ & 0.33 \\
\hline Expected Harvest of Others $\left(\beta_{4}\right)$ & $0.09 * * *$ & 0.01 \\
\hline Round $\left(\beta_{5}\right)$ & -0.01 & 0.01 \\
\hline Round $\times \operatorname{Com}\left(\beta_{6}\right)$ & 0.01 & 0.03 \\
\hline Round $\times$ LowPenalty $\left(\beta_{7}\right)$ & $0.07 * *$ & 0.03 \\
\hline Round $\times$ MidPenalty $\left(\beta_{8}\right)$ & $0.10 * * *$ & 0.03 \\
\hline Random Effects - Variances & Estimate & $\begin{array}{c}\text { Standard } \\
\text { Errors }\end{array}$ \\
\hline \multicolumn{3}{|l|}{ Between-Group } \\
\hline Open Access $\left(\sigma_{u 0}^{2}\right)$ & 0.00 & 0.00 \\
\hline $\operatorname{Com}\left(\sigma_{u 1}^{2}\right)$ & $0.98 * *$ & 0.47 \\
\hline Low Penalty $\left(\sigma_{u 2}^{2}\right)$ & 0.08 & 0.37 \\
\hline Mid Penalty $\left(\sigma_{u 3}^{2}\right)$ & 0.39 & 0.39 \\
\hline \multicolumn{3}{|l|}{ Within-Group } \\
\hline Open Access $\left(\sigma_{v 0}^{2}\right)$ & $0.71 * * *$ & 0.11 \\
\hline $\operatorname{Com}\left(\sigma_{v 1}^{2}\right)$ & 0.03 & 0.13 \\
\hline Low Penalty $\left(\sigma_{v 2}^{2}\right)$ & $3.01 * * *$ & 0.74 \\
\hline Mid Penalty $\left(\sigma_{v 3}^{2}\right)$ & $1.90 * * *$ & 0.51 \\
\hline
\end{tabular}

Within-Individual $-\left(\sigma^{2}\right) \quad 3.77 * * * \quad 0.09$

Asterisks reflect $\mathrm{p}$-values: ${ }^{*} p \leq 0.10 ;{ }^{* *} p \leq 0.05 ; * * * p \leq 0.01$. N=3600 (36 groups, 5 subjects per group, 20 rounds). 


\section{References}

Bornstein, G. and M. Ben-Yossef. 1994. "Cooperation in Intergroup and Single-Group Social Dilemmas.” Journal of Experimental and Social Psychology, 30, 52-67.

Boyle, Michael H. and J. Douglas Willms. 2001. "Multilevel Modeling of Hierarchical Data in Development Studies.” Journal of Child Psychology and Psychiatry, 42: 1, 141-162.

Brandts, Jordi and Arthur Schram. 2001. "Cooperation and Noise in Public Good Experiments: Applying the Contribution Function Approach.” Journal of Public Economics, 79, 399-427.

Brosig, Jeannette. 2002. "Identifying Cooperative Behavior: Some Experimental Results in a Prisoner’s Dilemma Game”. Journal of Economic Behavior and Organization, 47, 275-290.

Cardenas, Juan Camilo; John Stranlund and Cleve Willis. 2000. “Local Environmental Control and Institutional Crowding Out.” World Development, 28: 10, 1719-1733.

Cardenas, Juan Camilo, John Stranlund and Cleve Willis. 2002. "Economic Inequality and Burden-Sharing in the Provision of Local Environmental Quality.” Ecological Economics 40:3 , 379-395.

Cardenas, Juan Camilo, T.K. Ahn and Elinor Ostrom. 2003. "Communication and Cooperation in a Common Pool Resource Dilemma: A Field Experiment.” Forthcoming in Advances in Understanding Strategic Behavior: Game Theory, Experiments and Bounded Rationality: Essays in Honor of Werner Guth. Steffen Huck (Ed.), Palgrave, New York.

Casari, Marco and Charles R. Plott. 2003. "Decentralized Management of Common Property Resources: Experiments with a Centuries-old Institution.” Journal of Economic Behavior \& Organization, 51, 217-247.

Cason, Timothy N., Tatsuyoshi Saijo, Takehiko Yamato and Konomu Yokotani. 2004. “NonExcludable Public Good Experiments.” Games and Economic Behavior, 49, 81-102.

Cornes, Richard and Todd Sandler. 1983. “On Commons and Tragedies.” The American Economic Review, 73:4, 787-792.

Croson, Rachel T.A .1998. "Theories of Commitment, Altruism and Reciprocity: Evidence from Linear Public Good Games.” Working Paper, University of Pennsylvania.

Fischbacher, Uber, Simon Gachter and Ernest Fehr. 2001. “Are People Conditionally Cooperative? Evidence from a Public Goods Experiment.” Economics Letters, 71, 397-404.

Goldstein, Harvey. 1995. Multilevel Statistical Models. Second Edition. London: Edward Arnold.

Harrison, Glen W. and John List. 2004. “Field Experiments.” Journal of Economic Literature, 52, 1009-1055.

Hox, J. 1998. “Multilevel Modeling: When and Why.” In Classification , Data Analysis, and Data Highways. Ingo Balderjahn, Martin Schader, Rudolf Mathar (Eds.), New York: Springer Verlag.

Keser, Claudia and Frans van Winden. 2000. “Conditional Cooperation and Voluntary Contributions to Public Goods”. Scandinavian Journal of Economics, 102: 1, 23-39. 
Komorita, S. S.; C. D. Parks and L.G. Hulbert. 1992."Reciprocity and the Induction of Cooperation in Social Dilemmas.” Journal of Personality and Social Psychology, 62, 607617.

Kurzban, Robert; Kevin McCabe; Vernon L. Smith and Bart J. Wilson. 2001. "Incremental Commitment and Reciprocity in a Real-Time Public Good Game.” Personality and Social Psychology Bulletin, 27: 12, 1662-1573.

Kurzban, R. and Houser, D. 2005. "Experiments Investigating Cooperative Types in Humans: A Complement to Evolutionary Theory and Simulations.” Proceedings of the National Academy of Sciences, 102: 5, 1803-1807.

Messer, Kent; Todd Schmit, and Harry Kaiser. 2005. “Optimal Institutional Mechanisms for Funding Generic Advertising: An Experimental Analysis.” American Journal of Agricultural Economics, 87:4, 1046-1060.

Offerman, Theo; Joep Sonnemans and Arthur Scharam. 1996. "Value Orientations, Expectations and Voluntary Contributions in Public Goods”. The Economic Journal, 106:7, 817-845.

Ostrom, Elinor; James Walker and Roy Gardner.1994. Rules, Games, and Common pool Resources. The University of Michigan Press.

SAS Institute Inc. 1999. SAS OnlineDoc®, Version 8, Cary, NC: SAS Institute Inc.

Singer, Judith. 1998. Using SAS Proc Mixed to Fit Multilevel Models, Hierarchical Models and Individual Growth Models, Journal of Educational and Behavioral Statistics, 24: 4, 323-355.

Yamagishi, T. and K. Sato (1986). “Motivational Bases of the Public Goods Problem.” Journal of Personality and Social Psychology, 13, 135-151. 


\section{Reviewer's Appendix: Experiment Instructions ${ }^{13}$}

\section{Stage 1: Open Access Treatment (Open Access)}

Before we begin, we want to thank you all for accepting this invitation and participating in this exercise. The objective of this exercise is to understand how people make decisions related to the use of a shared natural resource. All the decisions you make, as well as all the other information you will provide us, will remain confidential. We will not divulge your individual decisions to any other member of the community, nor to any other person.

\section{Introduction}

The exercise in which you are going to participate can be different from other exercises in which members of your community might have participated in the past, therefore, any comment that you might have heard about the exercise does not necessarily apply to the version in which you will participate.

This exercise is similar to a situation in which a group of people have to make decisions on how to use a shared natural resource. For example, a forest, a drinking water source, or a fishing area. In this experiment, the resource will be referred as a fishery.

You have been selected to participate in a group of 5 people. Today, there are 3 groups participating at the same time. However, each group is independent and the decisions of the other groups do not affect the decisions of your group. Each group will be differentiated by the color of the sheets used during the exercise.

In this exercise you will earn money depending on your decisions and the decisions of the other members of your group. The reason why we use money in this exercise is to represent real life situations in which your economic decisions will bring yourself monetary consequences. You will play several rounds equivalent, for example, to periods such as years, months, or fishing seasons.

In each round, you will earn a number of points that will be equivalent to a number of pesos. At the end of the exercise, we will sum the total number of pesos earned in all the rounds, we will round the total earned, and we will personally hand that to you in cash.

We will now explain how to participate in the exercise. Please pay a lot of attention to the instructions. If you understand the instructions, you will be able to make better decisions in the exercise. Please, remain seated and do not speak with other participants. If you have a question, raise you hand. The assistant will answer your question in private.

\section{Earnings Table}

We will now hand out the EARNINGS TABLE which contains all the information you will need to make your decisions in this exercise.

\footnotetext{
${ }^{13}$ Thanks to Juan Camilo Osorio for translating the instructions from Spanish to English.
} 
All participants have the same EARNINGS TABLE that you do. The numbers in the table are points equivalent to the pesos you can earn in each round, depending on both what you decide to extract and the decisions made by others in your group.

In each round you have to decide how many units of the resource you will extract. We will call your decision "MY LEVEL OF EXTRACTION.” These units correspond to the columns 1 to 9 in the EARNING TABLE. In this exercise, each participant can extract a maximum of 9 units, and a minimum of 1 .

In the EARNINGS TABLE, the decisions of the other members of your group correspond to the column "LEVEL OF EXTRACTION OF OTHERS", which will be a number between 4 and 36. This number is the sum of the units extracted by the other members of the group. In other words, "LEVEL OF EXTRACTION OF OTHERS" is equal to: the total extraction of the whole group, minus the amount you extracted. When you make your decision, you will not know the decisions made by the other members of your group.

Once all participants hand in their decisions, we will sum all the levels of extraction and will announce the group's TOTAL LEVEL OF EXTRACTION. With this information you will be able to calculate the "LEVEL OF EXTRACTION OF OTHERS," which is equal to the “TOTAL LEVEL OF EXTRACTION” minus "MY LEVEL OF EXTRACTION".

Let's see some examples so that you can understand how to use the EARNINGS TABLE.

Imagine you decide that "MY LEVEL OF EXTRACTION" is 4 units, and that the other members of the group extract 4 units each. We will announce that the TOTAL level of extraction is 20 units. Since you decided to extract 4, you can calculate the "LEVEL OF EXTRACTION OF OTHERS," which is equal to the "TOTAL LEVEL OF EXTRACTION" minus "MY LEVEL OF EXTRACTION". In this case, the "LEVEL OF EXTRACTION OF OTHERS" is $20-4=16$ units. Thus, as seen in the table, your earnings will be 859 .

In the previous example all the members of the group picked the same level of extraction. However, each person can pick a different number. For example, if you choose 4 and the other members of the group extract 2, 3, 7 and 8, we will announce that the TOTAL level of extraction is 24. Given the fact that you decided to extract 4, the "LEVEL OF EXTRACTION OF OTHERS" will be 20. In other words, the "TOTAL LEVEL OF EXTRACTION (24) minus "MY LEVEL OF EXTRACTION" (4). In this case, as seen on the table, your earnings will be 754.

The EARNINGS TABLE has an additional table called “Average of others". This column indicates you the average decision of your group for a determined level. For example, if the others extract 8 , this means that the average amount extracted per person is 2. Instead, if the others extract 20 , the average amount extracted per person is 5 .

Take a few seconds to look at the EARNINGS TABLE and understand how it works. If you have any questions, please raise your hand and someone will come to you. 


\section{Decision Card}

I will now explain how you will inform us in each round your level of extraction. In each round you will receive a "decision card". The decision cards are these small pieces of paper.

\begin{tabular}{|c|c|}
\hline \multicolumn{2}{|c|}{ DECISION CARD } \\
\hline Participant Number: & \\
\hline Round Number: & \\
\hline $\begin{array}{c}\text { My level of extrac1tion: } \\
\text { (a number between 1 -9): }\end{array}$ & \\
\hline $\begin{array}{c}\text { How much do you think } \\
\text { others will extract? } \\
\text { (a number between 4 -36): }\end{array}$ & \\
\hline
\end{tabular}

In each round you will have to write:

- The number of the round, which will be announced by us.

-"MY LEVEL OF EXTRACTION”, in other words, how many units will you extract, which in this case will be a number between 1 and 9 .

-You also have to write what you think the other members of your group will extract.

This is the sum of the levels of extraction that you think the other 4 members of your group will extract. This sum is a number between 4 and 36. Remember that when you make your decision you do not know what the others are choosing. However, we want to know how much you think the others will extract. For example, if you think that two people will choose 3 and the other two 5 , then, what you think the others will extract is $16(3+3+5+5)$.

What you write on the level of extraction of others will not affect your earnings, either if it is equal or different to what actually happened. However, we are interested to know what you are thinking about the level of extraction of the others when you make your choice.

After all the members of your group have made their decisions, we will pick up the 5 participants' cards and calculate the groups' TOTAL level of extraction. Once we announce the total extraction of the group you will be able to calculate the true "LEVEL OF EXTRACTION OF OTHERS.” With this information and your level of extraction, you will be able to calculate how much you earned by looking at the EARNINGS TABLE.

It is very important that you remember that your decisions are private and that you can not show them to the other members of the group. We will only announce the TOTAL level of extraction. 


\section{Calculation sheet}

Each one of you will receive a calculation sheet with which you record your decisions and earnings. Please write your participant number in the calculation sheet. This is the same number that is written in the decision cards.

Let's see how to use the calculation sheet by looking at an example. Suppose you decided to extract 4 units. In consequence, you have to write 4 under column A of the calculation sheet, as shown in the example. You should also write this number in "MY LEVEL OF EXTRACTION" in the Decision Card .You are writing your decision in two places, in the Decision Card, which you will hand in back to us, and in the calculations sheet. Please, check that you have written the same number in the two sheets before you hand in the decision card.

After all the members of the group have finished taking their decisions, we will pick up the cards of the 5 participants and calculate the groups' TOTAL level of extraction.

Suppose the "TOTAL LEVEL OF EXTRACTION" is 20 units. You should write 20 in the column $B$ in the calculations sheet. In order to calculate accurately the "LEVEL OF EXTRACTION OF OTHERS," you should subtract Column A ("MY LEVEL OF EXTRACTION") from Column B (“TOTAL LEVEL OF EXTRACTION”) You should write the result in Column $C$ ("LEVEL OF EXTRACTION OF OTHERS") In our example, the “LEVEL OF EXTRACTION OF OTHERS” is $16(20-4$.

In order to calculate your earnings, you should use the EARNINGS TABLE. In this case, given that "MY LEVEL OF EXTRACTION" is 4 and the "LEVEL OF EXTRACTION OF OTHERS" is 16 , then your earnings will be 859 . This is the information you should write in column D.

\section{Practice rounds}

Before we begin the exercise we will do some practice rounds. The decisions that you take in these practice rounds would not affect your earnings today.

The first practice round will be done altogether. First, write the number of the round in the decision card, in this case (P) of practice. After that, looking at the EARNINGS TABLE suppose that each one of you picked 5. Write this in the decision card and in Column A of the earnings sheet. You should also write in the decision card what you think the other members of your group will extract. In this case, it is 20, because we know that all of them picked 5. Remember, when we begin the real exercise, you will not know the exact number of extraction of the other members while you will be picking your level of extraction. In the next rounds you will write what you think the others will extract.

Given that all the members of the group picked 5 in this example, the total level of extraction for the group is 25. Each one should write now 25 under Column B ("TOTAL LEVEL OF EXTRACTION”) in the calculations sheet.

Now subtract "MY LEVEL OF EXTRACTION" (5) from the "TOTAL LEVEL OF EXTRACTION” (25). In other words, column B minus Column A. This operation is equal to 20. This number is the true "LEVEL OF EXTRACTION OF OTHERS", which you should write in 
Column C. Using the number in Column A, "MY LEVEL OF EXTRACTION," and the number under column C, the "LEVEL OF EXTRACTION OF OTHERS", you should use the earnings table to determine your earnings for this round. In this case, your earnings will be 790 . Write your earnings in column D.

We did this example and the previous one supposing that everyone picked the same level of extraction. However, when you make your decision, you may choose the level of extraction that you want by looking at the EARNINGS TABLE. Are there any questions?

Let's continue with the next practice round. First, write down the round's name in the decision card, in this case (P) of practice. Now, each one of you has to decide your level of extraction using the EARNINGS TABLE. Write it down in the decision card and in Column $\mathrm{A}$ in the calculations sheet. Before you hand in the decision card, check that the number in column A is equal to the one you wrote in "MY LEVEL OF EXTRACTION" in the decision card. You should also write in the decision card the level of extraction that you believe the other members of the group will extract. 


\section{Stage 2 - Communication Treatment (Com)}

We now will begin the second part of this exercise. This part is very similar to the previous one, with the difference that in the next rounds you will be able to communicate with the other members of your group.

At the beginning of each round, before you decide how much you will extract, you will have 5 minutes to discuss the exercise with the other members of your group. During these 5 minutes, you will be able to discuss with them anything related with the exercise. Before the discussion round begins, turn your calculations sheet upside down and leave it on the table. After 5 minutes, the discussion will come to an end and you will return to your seat to decide privately what your level of extraction decision will be.

\section{Stage 2 - Mid Penalty Treatment (Mid Penalty)}

(These are the instructions for the medium penalty of 165. The instructions for the low penalty treatment are identical, except that the penalty for each additional unit extracted is 27).

We will now begin the second part of this exercise. This part is very similar to the previous one, with the difference that in the next rounds we will establish a regulation. The objective of this regulation is to make all participants of your group extract $\mathbf{2}$ units.

In order to promote that people do not extract more than 2 units of the resource, we are going to impose a penalty of 165 points for each additional unit extracted. The table that we will be handing out summarizes the total penalties that result from each level of extraction.

(Hand out the tables and explain them)

Penalty Table

\begin{tabular}{|c|c|c|c|c|c|c|c|c|c|}
\hline $\begin{array}{c}\text { My level of } \\
\text { extraction }\end{array}$ & $\mathbf{1}$ & $\mathbf{2}$ & $\mathbf{3}$ & $\mathbf{4}$ & $\mathbf{5}$ & $\mathbf{6}$ & $\mathbf{7}$ & $\mathbf{8}$ & $\mathbf{9}$ \\
\hline Penalty & 0 & 0 & 165 & 330 & 495 & 660 & 825 & 990 & 1155 \\
\hline
\end{tabular}

You will have to pay the penalty only if you are inspected when extracting more than 2 units of the resource. In other words, you can extract more than 2 units, but if you are inspected, you will have to pay the penalty. However, it will be very difficult to inspect the decisions of all the members of the group.

In consequence, once each person decides their level of extraction (a number between 1 and 9) and has handed in the decision card, we will randomly pick who will be inspected.

In order to decide who will be inspected, we will take a ballot from a bag containing 5 ballots with the participants' numbers on them, and 5 other blank ballots. 


\section{(Show the ballots)}

This implies that for each round you have ONE chance in 10 of being inspected. If your number is selected and you extracted more than 2 units of the resource, then you will have to pay the penalty for every additional unit. Nobody else will ever know the result of such inspection. If a blank ballot is selected, no one will be inspected.

\section{(Practice picking the ballot)}

In each round we will only take one ballot. The selected ballot will be returned to the bag. This means that the result of the inspection in this round will not affect the result of the next one. In this way, someone can be inspected more than one time during the exercise. It is also possible that you never get inspected.

\section{Let's make some examples:}

For example, if you extract 5 units of the resource, your level of extraction is 3 units greater than the permitted level of 2 units.

If your number is randomly selected from the bag, then you will be inspected. Since you extracted 5 units, the penalty will be 495 , as can be seen in the penalty table ( $5-2=3$ and $3 * 165=495)$. In consequence, we will have to subtract 495 from your earnings.

If a blank ballot is selected nobody will be inspected and we will follow on to the next round. If you are not inspected, you will not have to pay any penalty.

Another example:

If you extract 2 units, your level of extraction is equal to the level permitted. If your number is randomly selected from the bag, you will be inspected. Given the fact that your level of extraction is equal to the permitted level, then you will not have to pay the penalty. If a blank ballot is selected, nobody will be inspected and we will pass to the next round. If you are not inspected, you will not have to pay the penalty.

\section{Calculation sheet}

The calculation sheet for these rounds is very similar to the one used in the previous rounds, but includes some changes.

Before we begin, please write your participant's number in the new calculation sheet.

Columns A, B and C are used as in previous rounds. In column D you must write your earnings before you know if you will be inspected. Now, there are two additional columns. In column E you must write whether you were inspected or not in each round. Write YES or NO. In column $\mathrm{F}$ we will write the total value of the penalty you will have to pay if you are inspected. If you were not inspected, please write 0 in this column. In the last column, column G, you can write your earnings after the inspection. Earnings after the inspection are calculated subtracting the value of the penalty (column F) from the earnings before the inspection (column D). If you were not inspected, or your penalty is 0 , your earnings (column $G$ ) will be exact to what was written in column D (My earnings before the inspection).

Let's see some examples: 
Suppose that your level of extraction was 5 units and the total level of extraction was 17 units. Write this information in the corresponding columns as in the previous rounds. In this case, level of extraction of the others is 12 (column C) and your earnings will be 1021, before the inspection.

If your number is randomly selected from the bag, then you will be inspected. Write "YES" in column E. Since you extracted 5 units, the penalty will be 495, as you can see in the penalty table (5-2 =3 and 3*165=495.) Write 495 in column F (total penalty value.) In consequence, your total earnings for this round will be 1021 (column D) - 495 (column F) $=526$. Write 526 in the last column (My earnings after the inspection, column G.)

If a blank ballot is selected and nobody is inspected we will pass the following round. You will not have to pay any penalty. Write NO in column E, 0 in column F (penalty value) and write your earnings before the inspection (column D) in column $\mathrm{G}$ (earnings after the inspection.) 
EARNINGS TABLE

\begin{tabular}{|c|c|c|c|c|c|c|c|c|c|c|}
\hline & \multicolumn{9}{|c|}{ My level of extraction } & \multirow[b]{2}{*}{$\begin{array}{c}\text { Average } \\
\text { of the } \\
\text { others }\end{array}$} \\
\hline $\begin{array}{c}\text { Level of } \\
\text { extraction } \\
\text { of others }\end{array}$ & 1 & 2 & 3 & 4 & 5 & 6 & 7 & 8 & 9 & \\
\hline 4 & 900 & 996 & 1087 & 1172 & 1252 & 1326 & 1395 & 1458 & 1516 & 1.0 \\
\hline 5 & 882 & 976 & 1064 & 1146 & 1223 & 1295 & 1361 & 1421 & 1476 & 1.3 \\
\hline 6 & 864 & 955 & 1040 & 1120 & 1194 & 1263 & 1326 & 1384 & 1436 & 1.5 \\
\hline 7 & 846 & 934 & 1017 & 1094 & 1165 & 1231 & 1292 & 1347 & 1396 & 1.8 \\
\hline 8 & 829 & 914 & 994 & 1068 & 1137 & 1200 & 1258 & 1310 & 1357 & 2.0 \\
\hline 9 & 811 & 893 & 970 & 1042 & 1108 & 1168 & 1223 & 1273 & 1317 & 2.3 \\
\hline 10 & 793 & 873 & 947 & 1016 & 1079 & 1137 & 1189 & 1236 & 1277 & 2.5 \\
\hline 11 & 775 & 852 & 923 & 989 & 1050 & 1105 & 1154 & 1198 & 1237 & 2.8 \\
\hline 12 & 757 & 831 & 900 & 963 & 1021 & 1073 & 1120 & 1161 & 1197 & 3.0 \\
\hline 13 & 739 & 811 & 877 & 937 & 992 & 1042 & 1086 & 1124 & 1157 & 3.3 \\
\hline 14 & 721 & 790 & 853 & 911 & 963 & 1010 & 1051 & 1087 & 1117 & 3.5 \\
\hline 15 & 703 & 769 & 830 & 885 & 934 & 978 & 1017 & 1050 & 1077 & 3.8 \\
\hline 16 & 686 & 749 & 807 & 859 & 906 & 947 & 983 & 1013 & 1038 & 4.0 \\
\hline 17 & 668 & 728 & 783 & 833 & 877 & 915 & 948 & 976 & 998 & 4.3 \\
\hline 18 & 650 & 708 & 760 & 807 & 848 & 884 & 914 & 939 & 958 & 4.5 \\
\hline 19 & 632 & 687 & 736 & 780 & 819 & 852 & 879 & 901 & 918 & 4.8 \\
\hline 20 & 614 & 666 & 713 & 754 & 790 & 820 & 845 & 864 & 878 & 5.0 \\
\hline 21 & 596 & 646 & 690 & 728 & 761 & 789 & 811 & 827 & 838 & 5.3 \\
\hline 22 & 578 & 625 & 666 & 702 & 732 & 757 & 776 & 790 & 798 & 5.5 \\
\hline 23 & 560 & 604 & 643 & 676 & 703 & 725 & 742 & 753 & 758 & 5.8 \\
\hline 24 & 543 & 584 & 620 & 650 & 675 & 694 & 708 & 716 & 719 & 6.0 \\
\hline 25 & 525 & 563 & 596 & 624 & 646 & 662 & 673 & 679 & 679 & 6.3 \\
\hline 26 & 507 & 543 & 573 & 598 & 617 & 631 & 639 & 642 & 639 & 6.5 \\
\hline 27 & 489 & 522 & 549 & 571 & 588 & 599 & 604 & 604 & 599 & 6.8 \\
\hline 28 & 471 & 501 & 526 & 545 & 559 & 567 & 570 & 567 & 559 & 7.0 \\
\hline 29 & 453 & 481 & 503 & 519 & 530 & 536 & 536 & 530 & 519 & 7.3 \\
\hline 30 & 435 & 460 & 479 & 493 & 501 & 504 & 501 & 493 & 479 & 7.5 \\
\hline 31 & 417 & 439 & 456 & 467 & 472 & 472 & 467 & 456 & 439 & 7.8 \\
\hline 32 & 400 & 419 & 433 & 441 & 444 & 441 & 433 & 419 & 400 & 8.0 \\
\hline 33 & 382 & 398 & 409 & 415 & 415 & 409 & 398 & 382 & 360 & 8.3 \\
\hline 34 & 364 & 378 & 386 & 389 & 386 & 378 & 364 & 345 & 320 & 8.5 \\
\hline 35 & 346 & 357 & 362 & 362 & 357 & 346 & 329 & 307 & 280 & 8.8 \\
\hline 36 & 328 & 336 & 339 & 336 & 328 & 314 & 295 & 270 & 240 & 9.0 \\
\hline
\end{tabular}

